\title{
Ancient bird stencils discovered in Arnhem Land, Northern Territory, Australia
}

Paul S.C. Taçon ${ }^{1}$, Michelle Langley ${ }^{2}$, Sally K. May ${ }^{3}$, Ronald Lamilami ${ }^{4}$, Wayne Brennan ${ }^{5} \&$ Daryl Guse ${ }^{6}$

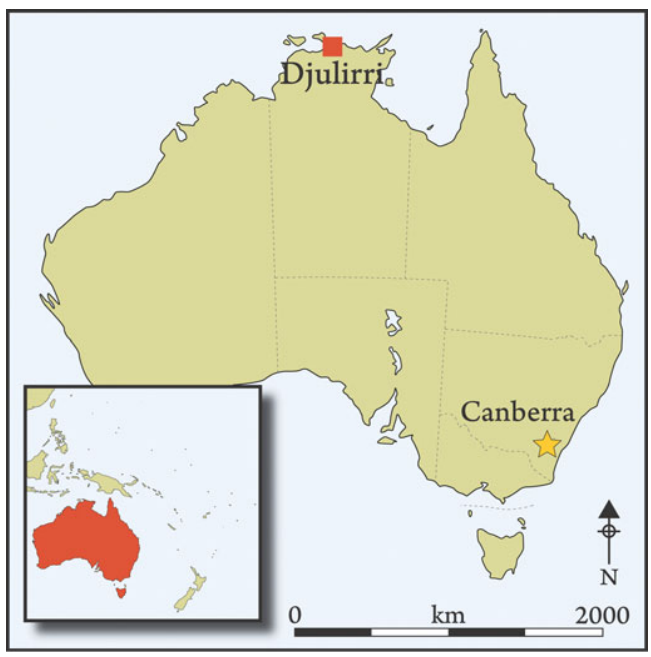

The discovery of rare bird stencils from a unique Australian rock art complex is reported, the species they most closely resemble is discussed and their significance in terms of world rock art and climate change is highlighted.

Keywords: Arnhem Land, Djulirri, rock art, stencils, bird images

\section{Introduction}

In July 2009 five stencils of the complete body of a bird were found on the wall and ceiling of a small rockshelter that is part of an extraordinary rock art complex known to the local Maung speaking Aboriginal people as Djulirri. Located in Arnhem Land's Wellington Range (Figure 1), the site has over 3100 paintings, prints, stencils and beeswax figures, making it

1 School of Humanities, Gold Coast Campus, Griffith University, Queensland 4222, Australia (Email: p.tacon@griffith.edu.au)

2 School of Social Science, The University of Queensland, St. Lucia Campus, Queensland 4072, Australia Research School of Humanities, The Australian National University, Canberra, ACT 0200, Australia

Kakadu Health Services, PO Box 721, Jabiru, Northern Territory 0886, Australia

Burramoko Archaeological Services, PO Box 217, Katoomba, New South Wales 2780, Australia

Department of Archaeology and Natural History, The Australian National University, Canberra, ACT 0200, Australia 


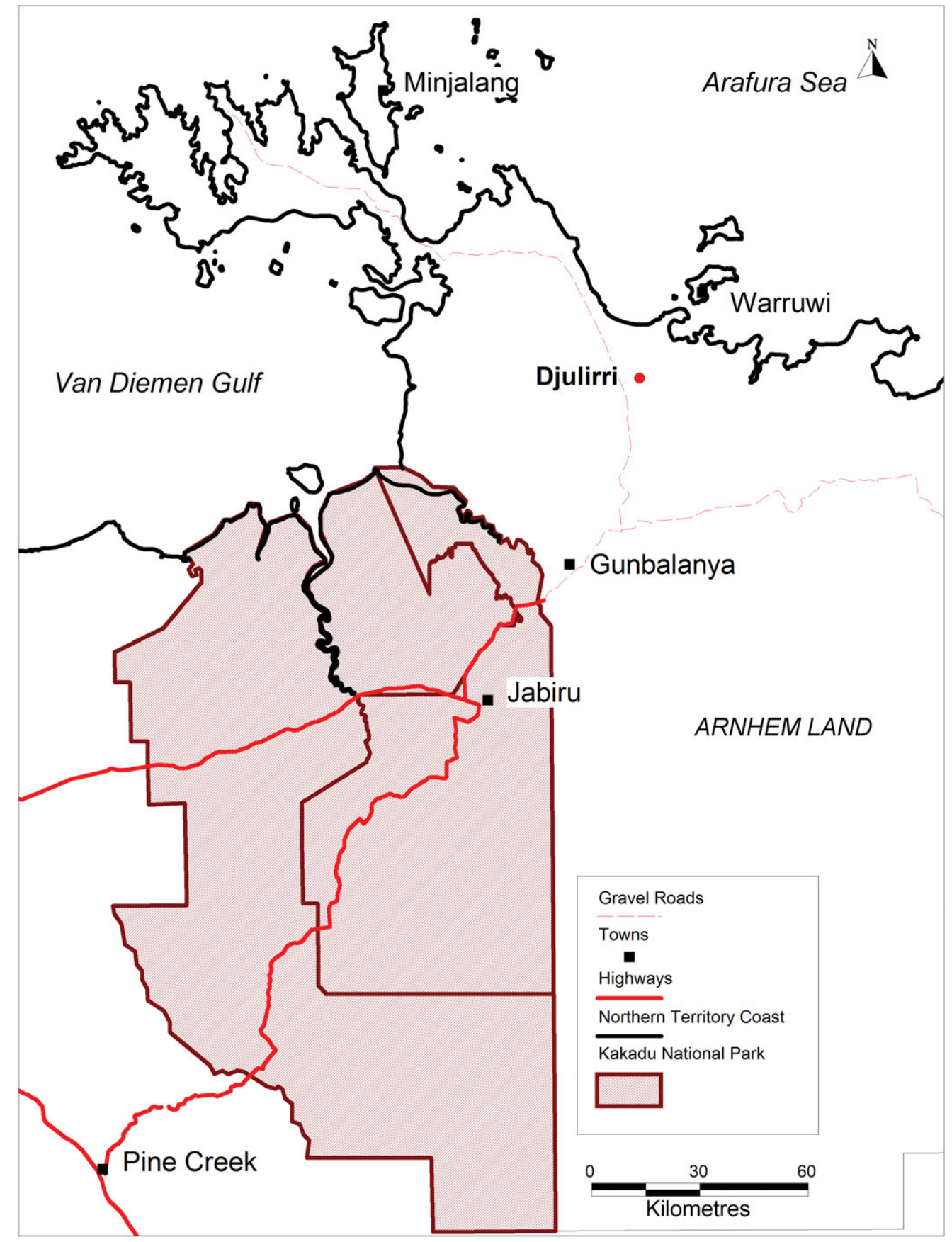

Figure 1. Location of Djulirri in Australia's Northern Territory. 
the largest pictograph (pigment) rock art site in Australia. Djulirri's main gallery has been visited and photographed by a handful of non-Aboriginal people since the 1950s but an intense recording and analysis of the site complex commenced in 2008. While recording 55 panels of imagery in detail the bird stencils were located in one of the more difficult to access areas. No other stencils of whole birds have been published from anywhere in the world, although a solitary example of a small bird stencil from elsewhere in Arnhem Land has been reported (Lewis 1988: 205). We describe and illustrate this unique rock art discovery, discuss the probable species of bird stencilled and present evidence that suggests considerable antiquity for the stencils.

\section{The Djulirri rock art complex}

Djulirri is located in the Wellington Range of Australia's Northern Territory, south of Goulbourn Island in Arnhem Land. Wellington Range is the northernmost outlier of the Kombolgie Sandstone that forms the famous Arnhem Land Plateau. Western Arnhem Land and the adjacent Kakadu National Park have long been famous for exquisite and extraordinary rock art with many thousands of sites documented and new discoveries made each year (Lewis 1988; Taçon 1989; Chaloupka 1993). The region boasts an impressive chronology with numerous styles, forms and subjects argued to have been produced from at least 15000 years ago to well after Aboriginal contact with people from Asia and Europe (Chippindale \& Taçon 1998). Djulirri is the largest art site within the Maung language group's traditional territory and today is at the western side of senior traditional owner Ronald Lamilami's clan estate. Lamilami's father, Lazurus, is believed to have taken the first non-Aboriginal person to the site, photographer Axel Poignant, in 1952 (Lamilami 1974; Poignant 1995). In the 1970s, George Chaloupka (1993) photographed and described parts of Djulirri's main gallery but further research did not take place until 2008 when an intensive recording program of the entire site commenced.

This recording program includes a number of other key sites in the region as well as a general survey of the Lamilami estate. A rock art chronology similar to that of Kakadu and other parts of Arnhem Land has been constructed and unique rock art subject matter, forms and styles associated with various periods of production, such as bird stencils, noted. In recent/ethnographic times rock paintings took place in key focal points within the Lamilami estate rather than occurring right across it, as in previous periods. The Lamilami family argue that there were various motivations for producing the art, including recording the arrival of newcomers such as Macassans and Europeans. They argue that in many ways their sites are like 'journals', 'history books' and 'libraries' that reflect changing times, relationships to land and other creatures, the power of Ancestral Beings that created and/or shaped the world and individual experience. However, with older forms of art the exact motivations are uncertain, as is the relevance of contemporary ontologies/cosmologies.

Across a $51 \mathrm{~m}$ length of dissected sandstone, Djulirri's main gallery has more than 1100 paintings, stencils, prints and figures made from the resinous wax of native bees in three adjacent wall/ceiling areas. There are another 52 panels within this complex with at least a further 2000 examples of rock art, making it the largest known pigment site yet documented in Australia. The complex is considered one extremely large site because each panel is less 
than $25 \mathrm{~m}$ from its neighbour, with the entire complex arranged in a horseshoe-like shape measuring about $180 \mathrm{~m}$ by $120 \mathrm{~m}$, oriented roughly northwest-southeast. A cluster of other sites can be found nearby.

Paintings made with combinations of reds, yellows and white that are typical of the region's recent rock art, including introduced contact period subject matter, are concentrated in Djulirri's main gallery and the rest of the southern wing of the horseshoe. Representative subject matter of all previous forms and styles is concentrated in the northern wing, with a few mixed sites towards the back. The site complex is unique in that across the Top End of the Northern Territory there are no other sites that display all Arnhem Land styles in one location. The Maung Traditional Owners consider Djulirri to be a virtual rock art library owing to the mix of local and other Arnhem Land styles.

The bird stencils (Figure 2) are located in one of the more difficult to access panels of the northern wing, in a sheltered part of an eroded sandstone outlier reached by a narrow passageway with high walls. This shelter (Figure 3 ) measures $10.5 \mathrm{~m}$ long by $7 \mathrm{~m}$ deep and up to $2.8 \mathrm{~m}$ high. It has a relatively stable rock surface with patches of a thin silicified crust on parts of the wall and ceiling surfaces, sometimes slightly overlapping stencils. There are some small boulders on the shelter floor but no major block collapse is apparent in this location. The floor does not have a deposit but some nearby shelters have excavation potential and the plain below the shelter has a deep deposit that is being considered for future excavation. Ongoing excavations by Guse at other Wellington Range sites suggest that the area has been intensively occupied for tens of thousands of years, in keeping with other areas of the Arnhem Land region (e.g. see Jones 1985).

There are 32 pictographs, consisting of 30 stencils, a yellow-red stick figure and a yellowred outline fish, scattered across a $4.6 \mathrm{~m}$ by $2.6 \mathrm{~m}$ ceiling area and a $3.4 \mathrm{~m}$ by $1.55 \mathrm{~m}$ adjacent wall. Most of the stencils are varying shades of dark red but a few yellow-red stencils superimpose darker ones and appear to have been made more recently, when the two figures were added. The dark stencils consist of open hands, with splayed fingers, a hand stencil with two of the fingers closed together (2MF) and the five bird body stencils. Each bird stencil is exactly the same shape and size, $21 \mathrm{~cm}$ long by $8 \mathrm{~cm}$ wide, suggesting that the same creature was stencilled five times (Figure 4).

\section{Animal and human body stencils}

Australia has one of the world's largest concentrations of rock art with at least 100000 known sites (Flood 1997: ix; Taçon 2001: 534). It also has much more frequent and varied stencil art than any other country or continent, with stencils of hands, hand-and-arms, material culture and sometimes feet common in many regions. This is very different to the rock art of other countries. For instance, stencils of any kind are unknown from many parts of the world, including much of Asia and southern Africa (Bahn 1998: 115). Where they do occur hands are most common and whole animals extremely rare.

In 2009 we also found a stencil of a whole fish at the north-east end of Djulirri. The only other whole animal stencils recorded from Arnhem Land are clustered at one site far to the south of the Wellington Range, documented by Lewis (1988: 205). He reports on stencils 


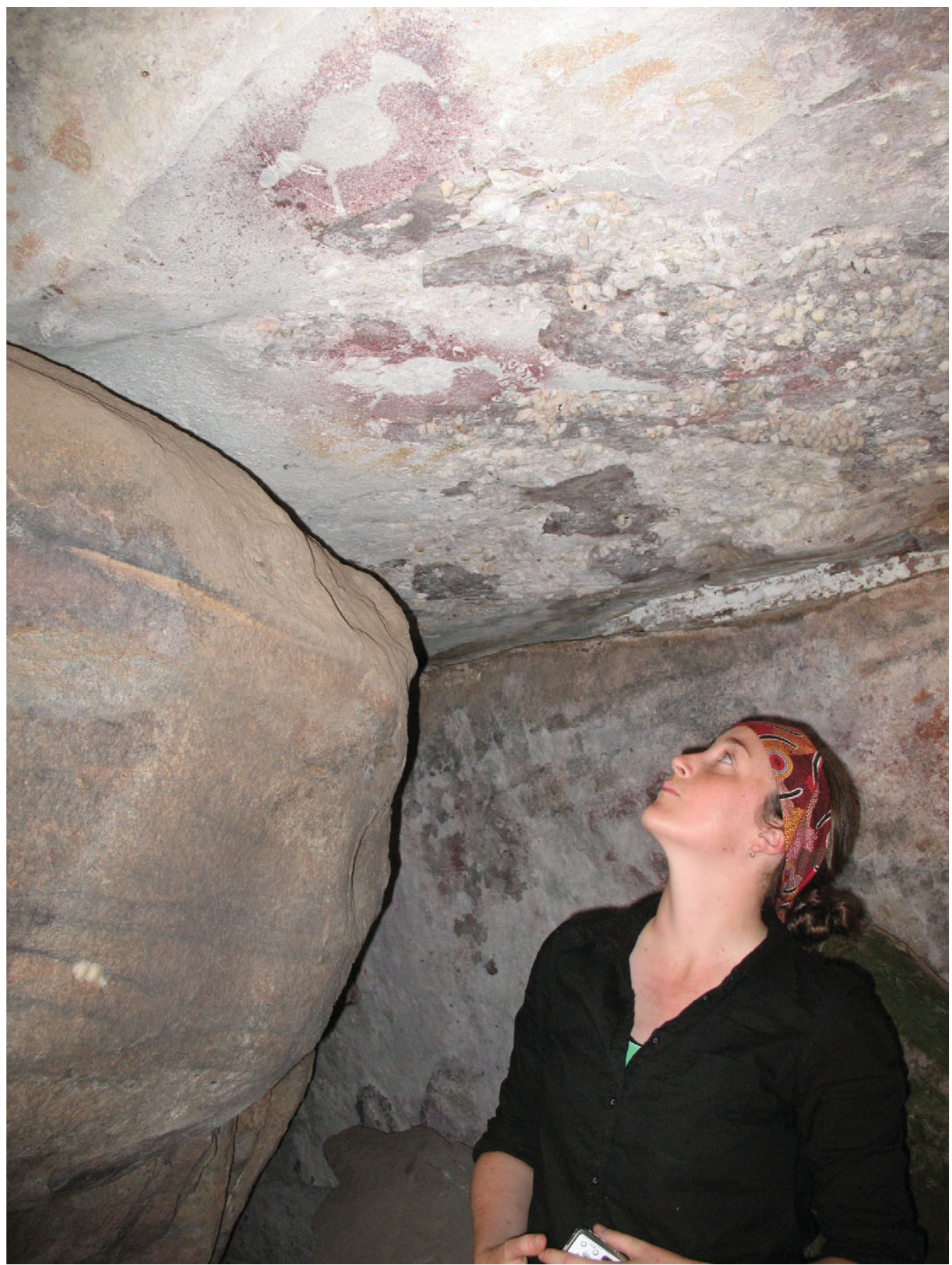

Figure 2. Michelle Langley observing newly discovered bird stencils on 21 July 2009. 


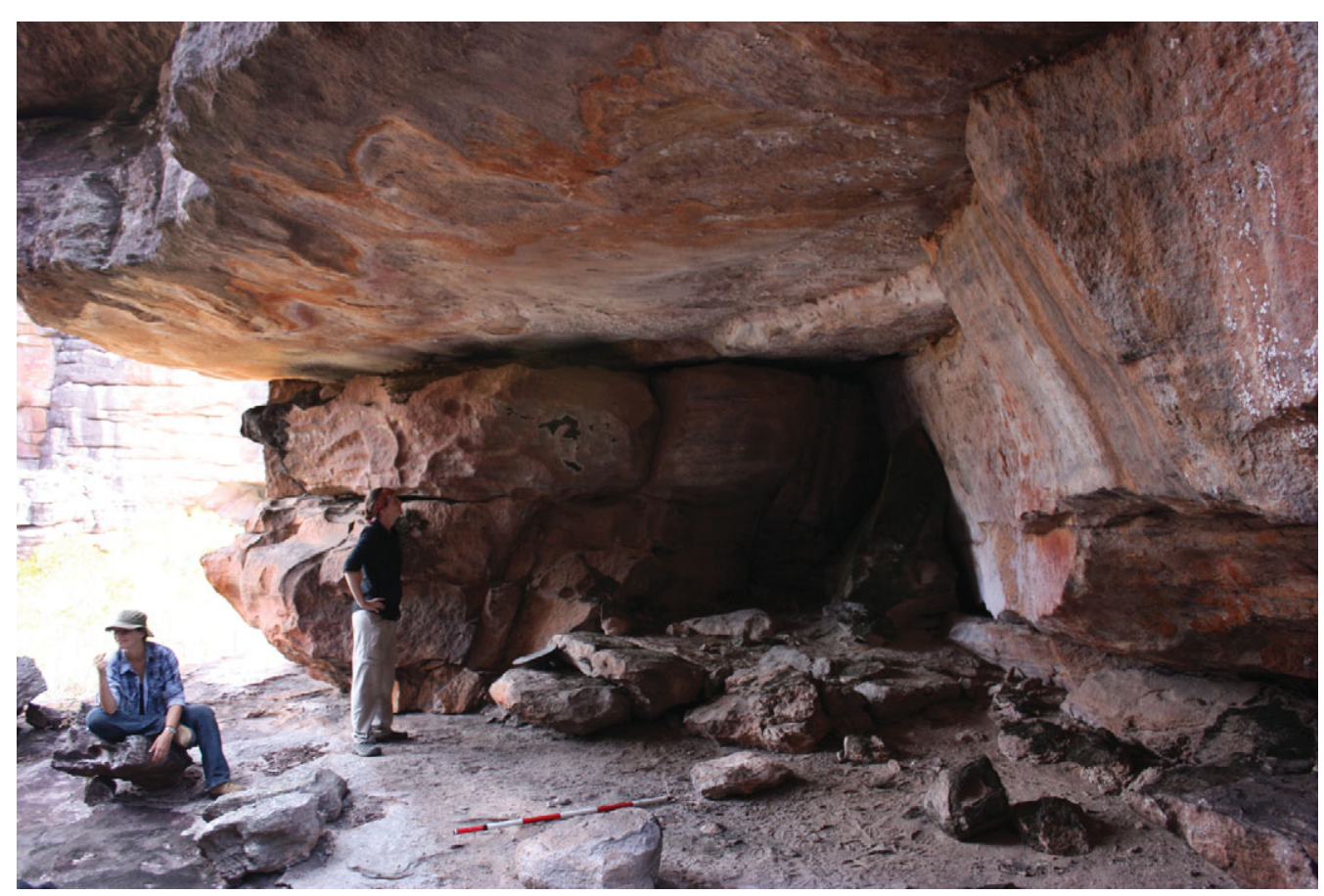

Figure 3. View of the stencil shelter.

of a possible gliding possum, a small mammal, a rat-like mammal, an animal leg and what 'appears to be a small bird'. Unfortunately, the possible bird stencil is not illustrated.

For Kakadu National Park, Taçon (1989) notes seven instances of animal body part stencils associated with recent X-ray paintings, five emu feet and two possible dingo paw stencils (see also Chaloupka 1993: 233). Eight emu foot stencils have also been documented in the Keep River region of the Northern Territory by one of us (PT). The hands, forearms, shoulders, neck and head of an adult human were stencilled at a site in Kakadu National Park (Taçon 1992: 214, fig. 8) and the whole upper torso of another adult was stencilled at a Cape York site, northern Queensland (recorded by PT, 1987). A virtually complete human body stencil has been recorded at The Tombs site, Mt Moffat Station, Queensland (Mulvaney \& Joyce 1965: 195 \& pl. 30). This site also has macropod leg stencils (Mulvaney \& Joyce 1965: 195 \& pl. 31). Nearby, at Carnarvon Gorge, stencils of emu feet, macropod feet, dog feet and snakes have been found (Quinnell 1979; Walsh 1983), as well as pieces of plants (Quinell 1979) and shells (Beaton \& Walsh 1977). Baler shell (Melo sp.) objects were also stencilled at The Walkunders site, north Queensland (Watchman \& Hatte 1996), while a lizard and a horse hoof were stencilled at Laura (Trezise 1971) and dingo paws, bird feet and a snake were stencilled on Middle Park Station, north-west Queensland (Wade 2009: 41).

For New South Wales, McDonald (2008: 63) illustrates stencilled fish tails from a site near the confluence of Cowan Creek and the Hawsksbury River and kangaroo tails from a shelter in Wollemi National Park, north-west of Sydney. She also notes that leaves and a 


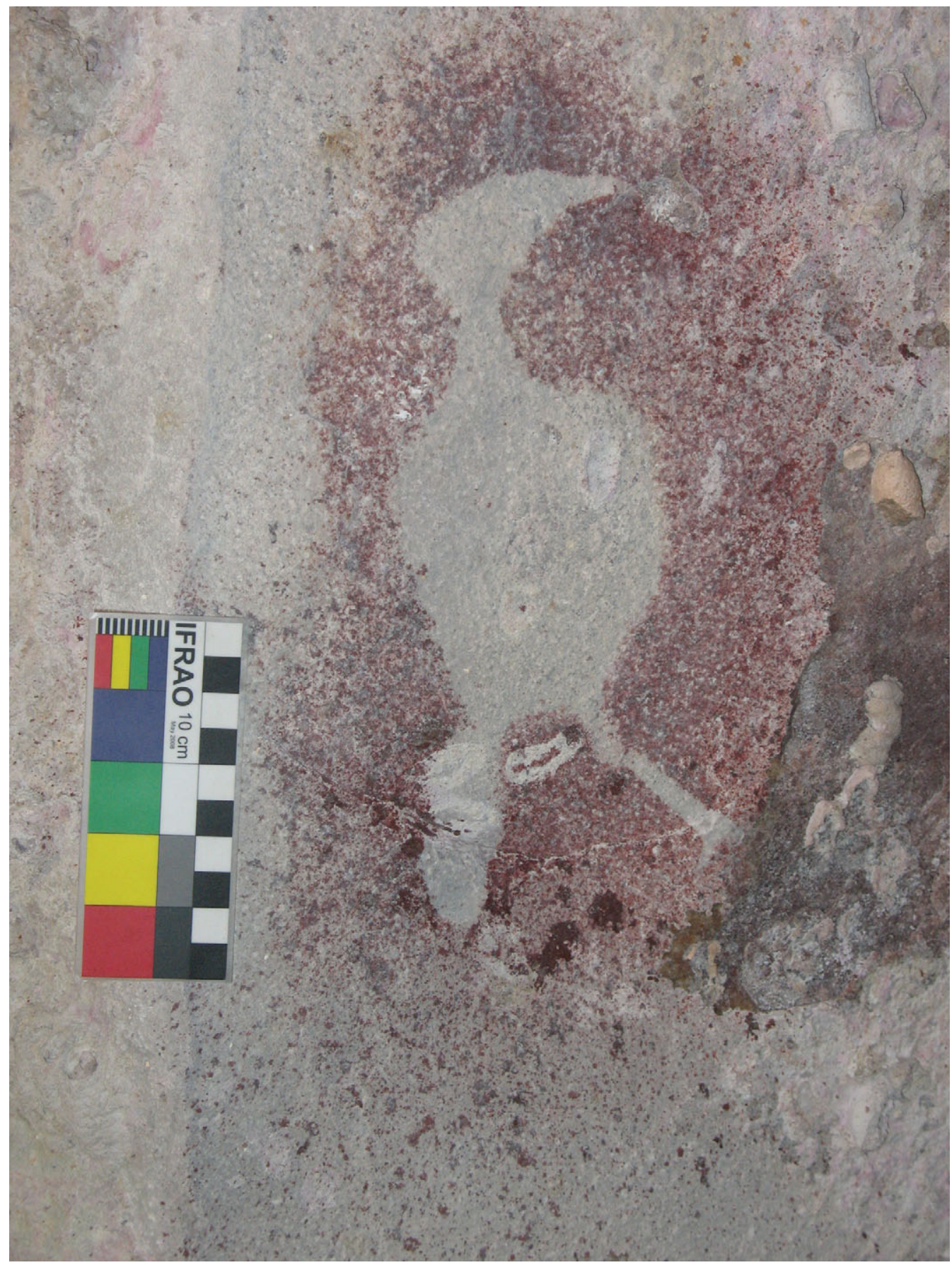

Figure 4. One of the best preserved bird stencils, on part of the ceiling that does not receive direct sunlight. 
twig were stencilled at the Great Mackerel rockshelter (McDonald 1992: 34). Sefton (1993: 63-4) recorded two 'mouse' stencils, five wallaby front feet and two wallaby back feet at sites on the Woronora Plateau, south of Sydney. Bindon (1976) documented a fish stencil and an unspecified animal foot at the nearby Shoahaven River. Officer (1984: 33) recorded two macropod feet and two emu feet in the Campbelltown Area of western Sydney while an unspecified animal foot stencil from Cobar has been reported (McCarthy 1976). Near Mootwingee there are five stencils of lizards, a bandicoot, a mammal skin and four snakes (McCarthy \& Macintosh 1962; see especially 264, fig. 8).

Throughout much of Australia many items of material culture were stencilled, especially boomerangs (Morwood 2002: 165-6). Walsh (1983) argues that many designs at Carnarvon Gorge sites and elsewhere are actually stencil composites. One of the more unusual object stencils is of a small human figure $12 \mathrm{~cm}$ high, probably made with a doll or a cut-out (Moore 1977: 319-20).

Outside Australia a stencil of a whole fish was recently found on the island of Tiga, New Caledonia, by Jacques Bolé and Christophe Sand (unpublished), while guanaco hoof stencils have been documented in Argentina (Podestá et al. 2005: 29, 81, pl. 14). Foot stencils of large flightless birds have been reported from Papua New Guinea (cassowary, Gorecki \& Jones 1988) and Patagonia in South America (ñandú or rhea, Podestá et al. 2005: 29, 83, pl. 15). However, most stencils outside Australia are of human hands and hands with forearms (especially in Europe, Argentina and on the island of Borneo) and these are also the most common forms of stencils within Australia (Layton 1992).

As has been demonstrated, stencils of whole animals and human bodies are very rare everywhere and, besides one reported sighting in Arnhem Land, bird stencils have not been found in any other part of Australia or anywhere else globally.

\section{Probable species and age of the stencils}

Because of the size of the stencilled bird, its distinctive head and beak shape and the nature of its tail, a short list of probable species can be constructed. However, given the skinny neck and smooth body lines, it appears that some throat and body feathers may have been plucked prior to stencilling, making precise identification difficult. Another possibility is that the bird neck may have been stretched from being held/gripped and carried with forefinger and thumb around the neck. This would have compressed the feathers, elongating the neck somewhat. The size and shape of the head suggests the bird is probably a honeyeater. Honeyeaters are common across Australia with many species currently reported from Arnhem Land alone. Most are either larger or smaller than the stencilled bird but the Singing Honeyeater (Lichenostomus virescens), with a length of 18-22 cm and similar shape, seems a likely candidate (see Pizzey 1985: 329, pl. 76). Today the Singing Honeyeater is rare in Arnhem Land, preferring drier environments to the south and avoiding areas of high rainfall.

This behavior and environmental preference could suggest the stencils were produced when the climate was much drier and Singing Honeyeaters presumably more common. For Arnhem Land, recent periods of aridity include the terminal Pleistocene and the mid to late Holocene (see Bourke et al. 2007 and Taçon \& Brockwell 1995 for reviews of Arnhem Land 
climate change in relation to archaeological data including rock art). The early Holocene was a wetter period while the mid to late Holocene was not only more arid but also a period of climatic variability due to the onset of ENSO conditions and wet-dry oscillations (e.g. see McGlone et al. 1992). The period of aridity during the terminal Pleistocene was less variable with climatic conditions similar to that of interior Australia today, the current range of the Singing Honeyeater.

This accords well with an association between the bird stencils and a hand stencil with two middle fingers (2MF) closed, as these and others with three middle fingers closed (3MF) are invariably associated with the oldest styles of rock art across Arnhem Land and other parts of northern Australia (Lewis 1988; Chaloupka 1993; Chippindale \& Taçon 1998). The $3 \mathrm{MF}$ stencil is widespread and almost like a 'logo' for early pre-estuarine art (Flood 1997: 267) while the $2 \mathrm{MF}$, although also associated with only the earliest art styles, is particular to the Wellington Range. In terms of his chronological sequence, Lewis (1988: 205) places the whole body animal stencils at a site far to the south of Djulirri in his 'Boomerang Period', arguing they are over 9000 years of age. Some of the Djulirri bird stencils have fossilised mud-wasp nests over them, again suggesting considerable antiquity for the stencils and providing potential for securing a minimum age (Roberts et al. 1997). Samples taken for AMS dating are in progress but all of the above suggests the bird stencils were made at least 9000 years ago, with the possibility of them being much older. Arnhem Land stencils of animals, including the Djulirri birds, are the oldest surviving animal-related stencils from anywhere. Those from elsewhere are known to be less than a few thousand or even a few hundred years of age given associated paintings and drawings, the nature of rock surfaces and regional dating programs (e.g. McDonald 2008).

\section{Implications and inspirations}

Nearby these remarkable stencils another panel was documented which provided evidence for an interesting relationship between the Djulirri sites. Remarkably, amongst over 200 paintings in another Djulirri shelter, three paintings of small birds clustered together were found on a low ceiling (Figure 5). They are of a similar size and shape to the much older stencilled birds and, we would argue, depict the same species. No other paintings of small species of birds were found at the site or at any of the hundreds of sites documented across the Wellington Range. These images, in solid yellow, appear to have been painted very recently, perhaps between 50-100 years ago, given their extremely fresh appearance and their style associated with recent European contact subject matter in Djulirri's main gallery. Is it possible that the older bird stencils documented in this paper inspired an artist in recent times to replicate accurately, from memory, the birds he saw in the stencil shelter as paintings?

Stencils, especially hands and feet, have been argued to be personal and individual markers (Moore 1977; Forge 1991; Taçon 1992; Chaloupka 1993; Rosenfeld 1993; Bahn 1998: 115). Lewis (1988: 205) suggests animal body stencils made at the site he recorded could have been made by children because they are within $1.5 \mathrm{~m}$ above ground. The five bird stencils at Djulirri, however, are about $2 \mathrm{~m}$ above ground on the ceiling and near the top of the wall. They were well executed and the bird held in place in such a way that 
Paul S.C. Taçon et al.



ปี

Figure 5. Two of three recently painted birds in yellow on the ceiling of a shelter about $80 \mathrm{~m}$ from the bird stencils. 
whatever held them was not stencilled. This suggests the artist had the skills and physical abilities of an adult.

We will never know why the bird was stencilled so many times in the one place. It may have been a rare treat for dinner, someone's totem species, a personal marker, a bird raised as a pet, the result of ritual, the product of an idle moment, a record of some significant event or an artistic innovation that never caught on. However, it reminds us of the long history of human interaction with and depiction of creatures both great and small. It also speaks to us about climate change and the threat to small, vulnerable species so often forgotten when human concerns dominate debate about environment and heritage.

\section{Acknowledgements}

This research was supported by Australian Research Council (ARC) Discovery Grant DP0877463 and is part of the Picturing Change research program. It is also supported by the Baijini, Macassans, Balanda, and Bininj research project and ARC Linkage Grant LP0882985. The Waminari Aboriginal community is thanked for logistical support and hospitality. The Northern Land Council is thanked for permits and advice. Jean Clottes, Sven Ouzman and Robert Bednarik are thanked for advice on the worldwide incidence of stencils. Christophe Sand, Jacques Bolé and Ian Lilley are thanked for permission to report their fish stencil discovery. Fellow Chief Investigators Sue O'Connor, Alistair Paterson and June Ross are thanked for support and collaboration on the research projects listed above. Griffith University and The Australian National University gave various forms of logistical support. Two anonymous referees are thanked for comments which improved this paper. Photographs are by P.S.C. Tacon.

\section{References}

BAHN, P. 1998. The Cambridge illustrated history of prehistoric art. Cambridge: Cambridge University Press.

Beaton, J. \& G. Walsh. 1977. Che-ka-ra. Mankind 11(1): 46-7.

BINDON, P. 1976. The devil's hands: a survey of the painted shelters of the Shoalhaven River basin. Unpublished BA dissertation, The Australian National University.

Bourke, P., S. BrockWell, P. FAUlKner \& B. MEEHAN. 2007. Climate variability in the mid to late Holocene Arnhem Land region, north Australia: archaeological archives of environmental and cultural change. Archaeology in Oceania 42(3): 91-101.

ChaloupKa, G. 1993. Journey in time. Sydney: Reed Books.

Chippindale, C. \& P.S.C. TAÇON. 1998. The many ways of dating Arnhem Land rock-art, in C. Chippindale \& P.S.C. Taçon (ed.) The archaeology of rock-art: 90-111. Cambridge: Cambridge University Press.

FlooD, J. 1997. Rock art of the Dreamtime. Sydney: Angus \& Robertson.
Forge, A. 1991. Handstencils: rock art or not art, in P Bahn \& A. Rosenfeld (ed.) Rock art and prehistory: papers presented to symposium $G$ of the AURA Congress, Darwin 1988 (Oxbow Monograph 10): 39-44. Oxford: Oxbow.

GORECKI, P. \& R. JONES. 1988. A new rock art province in New Guinea. Canberra: Department of Prehistory, The Australian National University.

JONES, R. (ed.) 1985. Archaeological research in Kakadu National Park. Canberra: Australian National Parks and Wildlife Service.

LAMILAMI, L. 1974. Lamilami speaks. Sydney: Ure Smith.

LAYTON, R. 1992. Australian Aboriginal art: a new synthesis. Cambridge: Cambridge University Press.

LEWIS, D. 1988. The rock paintings of Arnhem Land, Australia: social, ecological and material culture change in the post-glacial period (British Archaeological Reports International Series 415). Oxford: British Archaeological Reports.

MCCarthy, F.D. 1976. Rock art of the Cobar Pedeplain. Canberra: Australian Institute of Aboriginal Studies.

McCarthy, F.D. \& N.W.G. Macintosh. 1962. The archaeology of Mootwingee, western New South Wales. Records of the Australian Museum 25(13): 249-98. 
McDonald, J. 1992. The Great Mackerel rockshelter excavation: women in the archaeological record? Australian Archaeology 35: 32-50.

- 2008. Dreamtime superhighway: Sydney basin rock art and prehistoric information exchange (Terra Australis 27). Canberra: ANU E-Press.

McGlone, M.S., A.P. Kershaw \& V. Markgraf. 1992. El Niño/Southern Oscillation climatic variability in Australasian and South American paleoenvironmental records, in V. Markgraf \& H.F. Diaz (ed.) El Niño: historical and paleoclimatic aspects of the Southern Oscillation: 435-62. Cambridge: Cambridge University Press.

Moore, D. 1977. The hand stencil as symbol, in P.J. Ucko (ed.) Form in indigenous art: 318-24. Canberra: Australian Institute of Aboriginal Studies.

MORWOOD, M. 2002. Visions from the past. The archaeology of Australian Aboriginal art. Crows Nest: Allen \& Unwin.

Mulvaney, D.J. \& E.B. JOYCE. 1965. Archaeological and geomorphological investigations on Mt. Moffat Station, Queensland, Australia. Proceedings of the Prehistoric Society 31: 147-212.

Officer, K. 1984. From Tuggerah to Dharawal. Variation and function within a regional art style. Unpublished BA dissertation, The Australian National University.

Pizzey, G. 1985. A field guide to the birds of Australia. Sydney: Collins.

Podestá, M.M, R.S. Paunero \& D.S. Rolandi. 2005. El arte rupestre de Argentina indígena Patagonia. Buenos Aires: Grupo Abierto Communicaciones.

POIGNANT, R. 1995. Lost conversations, recovered archives. Tenth Eric Johnston Lecture 1995 (Occasional Paper 49). Darwin: Northern Territory Government. Available at: http//www.ntl.nt.gov.au/ _data/assets/pdf_file/0015/5262/occpaper49_ej10. pdf, accessed 3 August 2009.

QuINNELL, M.C. 1979. Schematisation and naturalism in the rock art of south central Queensland, in P.J. Ucko (ed.) Form in indigenous art: 415-17.

Canberra: Australian Institute of Aboriginal Studies.

Roberts, R., G. Walsh, A. Murray, J. Olley, R. Jones, M. Morwood, C. Tuniz, E. LaWson, M. MacPhail, D. Bowdery \& I. Naumann. 1997. Luminescence dating of rock art and mud-wasp nests in northern Australia. Nature 387: 696-9.
Rosenfeld, A. 1993. The Panaramittee tradition, in M. Smith, M. Spriggs \& B. Fankhauser (ed.) Sahul in review: Pleistocene archaeology in Australia, New Guinea and Island Melanesia: 71-80. Canberra: Department of Prehistory, RSPacS, The Australian National University.

Sefton, C. 1993. Stencil art on the Woronara Plateau: a description and analysis of sites and artefacts including stencils, charcoal drawings and petroglyphs. Rock Art Research 10(1): 61-4.

TAÇON, P.S.C. 1989. From Rainbow Snakes to 'X-ray' fish: the nature of the recent rock painting tradition of western Arnhem Land, Australia. Unpublished PhD dissertation, The Australian National University.

- 1992. Somewhere over the rainbow: an ethnographic and archaeological analysis of recent rock paintings of western Arnhem Land, Australia, in J.

McDonald \& I.P. Haskovec (ed.) State of the art: regional rock art studies in Australia and Melanesia: proceedings of symposium C'Rock art studies in Australia and Oceania' and symposium D 'The rock art of Northern Australia' of the First AURA Congress held in Darwin in 1988 (Occasional AURA

Publication 6): 202-15. Melbourne: Australian Rock Art Research Association.

- 2001. Australia, in D. Whitley (ed.) Handbook of rock art research: 530-75. Walnut Creek (CA): Altamira.

TAÇON, P.S.C. \& S. BROCKWELl. 1995. Arnhem Land prehistory in landscape, stone and paint. Antiquity 69: 676-95.

Trezise, P. 1971. Rock art of south-east Cape York. Canberra: Australian Institute of Aboriginal Studies.

WADE, V. 2009. Style, space and social interaction: an analysis of the rock-art on middle Park Station, northwest Queensland. Unpublished BA dissertation, Flinders University.

WaLsh, G. 1983. Composite stencil art: elemental or specialized? Australian Aboriginal Studies 2: 34-44.

Watchman, A. \& E. HATTE. 1996. A nano approach to the study of rock art: 'The Walkunders', Chillagoe, north Queensland. Rock Art Research 13(2): 85-92. 